\title{
Effect of sequential high-flow nasal cannula oxygen therapy and non-invasive positive-pressure ventilation in patients with difficult weaning from mechanical ventilation after extubation on respiratory mechanics
}

\author{
Shi-Ya Wang ${ }^{1 \#}$, Han-Wen Liang ${ }^{2 \#}$, Guang-Sheng Lu ${ }^{3 \#}$, Zhen-Jie Jiang ${ }^{1}$, Bao-Zhu Zhang ${ }^{1}$, Qiu-Xue Deng ${ }^{1}$, \\ Qing-Wen Sun ${ }^{1}$, Zhi-Min Lin ${ }^{1,4}$, Qiang Chen ${ }^{1}$, Chun Yang ${ }^{1}$, Yuan-Da Xu ${ }^{1,4}$, Ling Sang ${ }^{1,4}$ \\ ${ }^{1}$ National Clinical Research Center for Respiratory Disease, Guangzhou Institute of Respiratory Health, Department of Critical Care Medicine, The \\ First Affiliated Hospital of Guangzhou Medical University, Guangzhou, China; ${ }^{2}$ National Clinical Research Center for Respiratory Disease, State \\ Key Laboratory of Respiratory Disease, Guangzhou Institute of Respiratory Health, the First Affiliated Hospital of Guangzhou Medical University, \\ Guangzhou, China; ${ }^{3}$ Department of Critical Care Medicine, First People's Hospital of Zhaoqing, Zhaoqing, China; ${ }^{4}$ Guangzhou Laboratory, \\ Guangzhou, China \\ Contributions: (I) Conception and design: YD Xu, SY Wang, GS Lu; (II) Administrative support: None; (III) Provision of study materials or patients: \\ YD Xu, L Sang, ZM Lin, Q Chen, C Yang, QW Sun; (IV) Collection and assembly of data: SY Wang, ZJ Jiang, BZ Zhang; (V) Data analysis and \\ interpretation: HW Liang; (VI) Manuscript writing: All authors; (VII) Final approval of manuscript: All authors. \\ \#These authors contributed equally to this work. \\ Correspondence to: Yuan-Da Xu; Ling Sang. National Clinical Research Center for Respiratory Disease, Guangzhou Institute of Respiratory Health, \\ Department of Critical Care Medicine, The First Affiliated Hospital of Guangzhou Medical University, Guangzhou 510120, China; Guangzhou \\ Laboratory, Guangzhou 510320, China. Email: xuyuanda@sina.com; sonysang999@aliyun.com.
}

Background: Patients with difficult weaning who undergo mechanical ventilation are more likely to be at risk of reintubation and the sequential use of oxygen therapy after extubation is a concern for clinicians. Therefore, the aim of the present study was to compare the effects of transnasal high-flow nasal cannula (HFNC) oxygen therapy and non-invasive positive-pressure ventilation (NIV) on respiratory mechanics in patients with difficult weaning.

Methods: The present study was a single-center, retrospective, observational study. Twenty-nine patients with difficult weaning off invasive mechanical ventilation from the Department of Critical Care Medicine, The First Affiliated Hospital of Guangzhou Medical University, from December 2018 to April 2021, were included. Within $48 \mathrm{~h}$ after extubation, alternate respiratory support with HFNC and NIV was provided. Relevant indicators were recorded after each support mode had been maintained for at least $60 \mathrm{~min}$. These included esophageal pressure (Pes), gastric pressure (Pga), transdiaphragmatic pressure (Pdi), pressure-time product of Pes (PTPes), pressure-time product of Pga (PTPga), pressure-time product of Pdi (PTPdi), ratio of the PTPdi to the PTPes (PTPdi/PTPes), and ratio of the Pes to the Pdi (Pes/Pdi), diaphragmatic electromyogram (EMGdi), percentage of esophageal pressure coefficient of variation (CVes\%),diaphragmatic electromyogram coefficient of variation (CVEMG),inspiratory time (Ti), expiratory time (Te) and respiratory cycle time (Ttot).

Results: Of the 29 patients included, 22 were males and 7 were females [age: 63.97 \pm 15.34 years, Acute Physiological and Chronic Health Estimation II (APACHE II) score: 18.00 \pm 5.63$]$. The CVes\% and the Pes/ Pdi were significantly higher in patients with NIV than HFNC using $40 \mathrm{~L} / \mathrm{min}$, CVes\%: $9(-6,20)$ vs. -7 $(-23,6)$ and Pes/Pdi: 0.17 (-0.1, 0.53), vs. $-0.12(-0.43,0.08)(\mathrm{P}<0.05)$. The remaining indicators were not statistically different.

Conclusions: The sequential NIV and HFNC can be tolerated in patients with such difficult weaning off mechanical ventilation after extubation, and more patients tend to choose HFNC subjectively. Compared with HFNC, NIV reduces the work of adjunctive respiratory muscle, but the patient's Pes dispersion is high when NIV is used, and it is necessary to pay attention to patient-ventilator coordination in clinical practice. 
We recommend alternating HFNC and NIV during the sequential respiratory therapy after extubation.

Keywords: High-flow nasal cannula oxygen therapy; non-invasive positive-pressure ventilation (NIV); difficult weaning; respiratory mechanics

Submitted Jun 09, 2021. Accepted for publication Aug 05, 2021.

doi: 10.21037/atm-21-3408

View this article at: https://dx.doi.org/10.21037/atm-21-3408

\section{Introduction}

The proportion of patients on invasive mechanical ventilation who have difficult weaning is approximately $20-40 \%(1,2)$. These patients have significantly higher rates of failed extubation and reintubation. Sequential respiratory support after extubation improves prognosis and is used to prevent reintubation in critically ill patients (3). Non-invasive positive-pressure ventilation (NIV) has been used for many years to avoid reintubation and to improve prognosis, especially in patients with chronic obstructive pulmonary disease (COPD), hypercapnia, and acute cardiogenic pulmonary edema (4). According to the 2017 European Respiratory Society/American Thoracic Society (ERS/ATS) guidelines, it suggests that NIV be used to prevent post-extubation respiratory failure in high-risk patients (5). However, patients treated with NIV often suffer from aspiration errors, oro-nasopharyngeal dryness, mask compression, nasal and facial skin damage, difficulty in expelling sputum, pneumatic injuries, claustrophobic syndrome, and patient-ventilator dyssynchrony (6-8). More than $15 \%$ of patients develop NIV intolerance for various reasons, which increases the risk of treatment failure and reintubation $(9,10)$. In recent years, HFNC has also been increasingly used to prevent reintubation in patients at risk of failed extubation (11-13). NIV generates a fixed pressure support through a variable flow rate, while HFNC generates a variable pressure support by generating a constant high flow rate gas that is heated and humidified. HFNC has higher comfort and tolerance than NIV, but it provides Pressure support is low. Some studies have shown that HFNC reduces intensive care unit (ICU) length of stay compared with NIV (14). There is no difference in ICU mortality, length of ICU stay, reintubation (15). And HFNC is not inferior to NIV in preventing respiratory failure and reintubation in high-risk patients after extubation, including patients with COPD combined with hypercapnia, who are intubated for respiratory failure $(12,16)$. A recent RCT concluded that, in mechanically ventilated patients at high risk of extubation failure, the use of high-flow nasal oxygen with NIV immediately after extubation significantly decreased the risk of reintubation compared with high-flow nasal oxygen alone (17). Why is using NIV and HFNC alternately better than using HFNC alone? And there is no difference in using NIV or HFNC alone? We try to find the difference between NIV and HFNC from the perspective of respiratory mechanics, in order to realize the advantages and avoid disadvantages in clinical applications. We present the following article in accordance with the STROBE reporting checklist (available at https://dx.doi.org/10.21037/ atm-21-3408).

\section{Methods}

\section{Patient selection}

Twenty-nine patients with difficult weaning from invasive mechanical ventilation, admitted to the Department of Critical Care Medicine, The First Hospital of Guangzhou Medical University from December 2018 to April 2021, were included.

Difficult weaning was defined as patients who fail initial weaning and require up to three spontaneous breathing trial (SBT) or as long as 7 days from the first SBT to achieve successful weaning (18). According to our clinical protocol, all patients included met the 2007 ERS/AST weaning screening criteria.

\section{Exclusion criteria}

The exclusion criteria were as follows: (I) patients aged $<18$ years or $>80$ years; (II) hemodynamic instability; (III) contraindications to the placement of a multifunctional monitoring nasogastric tube, gastric and esophageal lesions and malformations, severe bleeding and coagulation abnormalities, post-pyloric feeding, recent upper gastrointestinal surgery, or esophagogastric fundic varices; (IV) those who were pregnant; (V) diagnosed with 
bronchopleural fistula; (VI) intra-abdominal hypertension or a history of abdominal surgery in the past month; (VII) severe cardiac arrhythmias or pacemaker implants; (VIII) relative contraindications to NIV, including increased secretions; (IX) deep sedation or neuromuscular blocking agents used within $48 \mathrm{~h}$; and $(\mathrm{X})$ patient or family refusal.

\section{Ethics}

The study complied with medical ethics standards and was approved by the Ethics Committee of the First Affiliated Hospital of Guangzhou Medical University (approval No.: 2020-159). Informed consent was obtained from the patient or next of kin for treatment and monitoring. All procedures performed in this study involving human participants were in accordance with the Declaration of Helsinki (as revised in 2013). This study has been registered in the Chinese Clinical Trial Registry (registration No.: ChiCTR2100044634).

\section{Monitoring}

A multifunctional transesophageal monitoring gastric tube (Guangzhou Institute of Respiratory Health, Guangzhou, China) was insert through the nasal cavity of the patient after signing the informed consent form. The multifunctional transesophageal monitoring gastric tube $(14 \mathrm{~F})$ consists of an esophageal sac, a gastric sac, gastric tube, and 10 electrodes, which is self-contained with a barium non-developing line, and is left in place to ensure that the esophageal sac is located in the middle and lower third of the esophagus by using $\mathrm{X}$-rays. The versatile transesophageal monitoring of the gastric tube does not interfere with daily nasal feeding, and therefore allows dynamic monitoring of the respiratory mechanics of patients on sequential respiratory support after weaning.

\section{Airtightness check and inflation}

When measurement data are required, the airtightness of the airbag must first be determined. The gastric and esophageal bursa tubes of the multipurpose gastric tube are connected to the 2 manometry tubes via a medical threeway pipe. Connected a $5 \mathrm{~mL}$ syringe to the place where the medical three-way pipe communicates with the atmosphere. The valve is then rotated so that the manometer tube is locked in the direction of the syringe, and the gastric capsule is opened in the direction of the syringe. The syringe is drawn to a negative pressure and then relaxed; it is left to retract naturally and then fixed. Then rotate the valve until the three sides are locked, remove the syringe, draw $2 \mathrm{~mL}$ of air, connect the syringe again to the connection between the IV tee and the outside world, rotate the tee until all three sides are open, inject $2 \mathrm{~mL}$ of air into the gastric sac, draw back $0.8 \mathrm{~mL}$ of air and rotate the tee so that the gastric sac is open in the direction of the manometer tube and locked in the direction of the outside air. Repeat for the esophageal sac, but after injecting $2 \mathrm{~mL}$ of air, pump back $1.2 \mathrm{~mL}$ of gas.

\section{Connections}

The DP 15 pressure sensor is connected to the CD280 pressure amplifier (Validyne Engineering Corp., Northridge, California, USA), the diaphragm myoelectric signal is converted by the bioelectric amplifier (ADInstruments, Bella Vista, Sydney, New South Wales ,Australia) and then input into the Powerlab 16/35 (ADInstruments, Bella Vista, Sydney, New South Wales ,Australia), and then connected to the Labchart 7 (ADInstruments, Bella Vista, Sydney, New South Wales, Australia) of the computer.

\section{Measurements and values}

Five EMGdi channels were visible in the LabChart software, as well as 3 pressure curves. The first and fifth channels had maximum EMGdi signals and the third channel had the minimal EMGdi signal. The root mean square values of the EMGdi signals were generated offline with a time constant of $100 \mathrm{~ms}$ and calculated automatically by LabChart7 software. Of the pressure curves, curve 1 responds to Pga (in response to intra-abdominal pressure), curve 2 to Pes (in response to intrathoracic pressure), and curve 3 to Pdi, at the same time. The pressure-time product (PTP) was calculated as the corresponding area curve under 1 respiratory period, and the PTP during 5 smooth breaths was taken and averaged to obtain the corresponding PTPes, PTPga, and PTPdi. Calculation of the percentage of coefficient of variation $(\mathrm{CV} \%)$ was as follows: $\mathrm{CV} \%=$ $\mathrm{SD} / \mathrm{MN} \times 100 / \%$, where SD is the standard deviation and $\mathrm{MN}$ is the mean. We calculated the CV of Pes and EMGdi according to this formula.

After extubation, the patient was ventilated with HFNC or NIV in a sequential manner. We monitored only the respiratory mechanic parameters for $48 \mathrm{~h}$, 


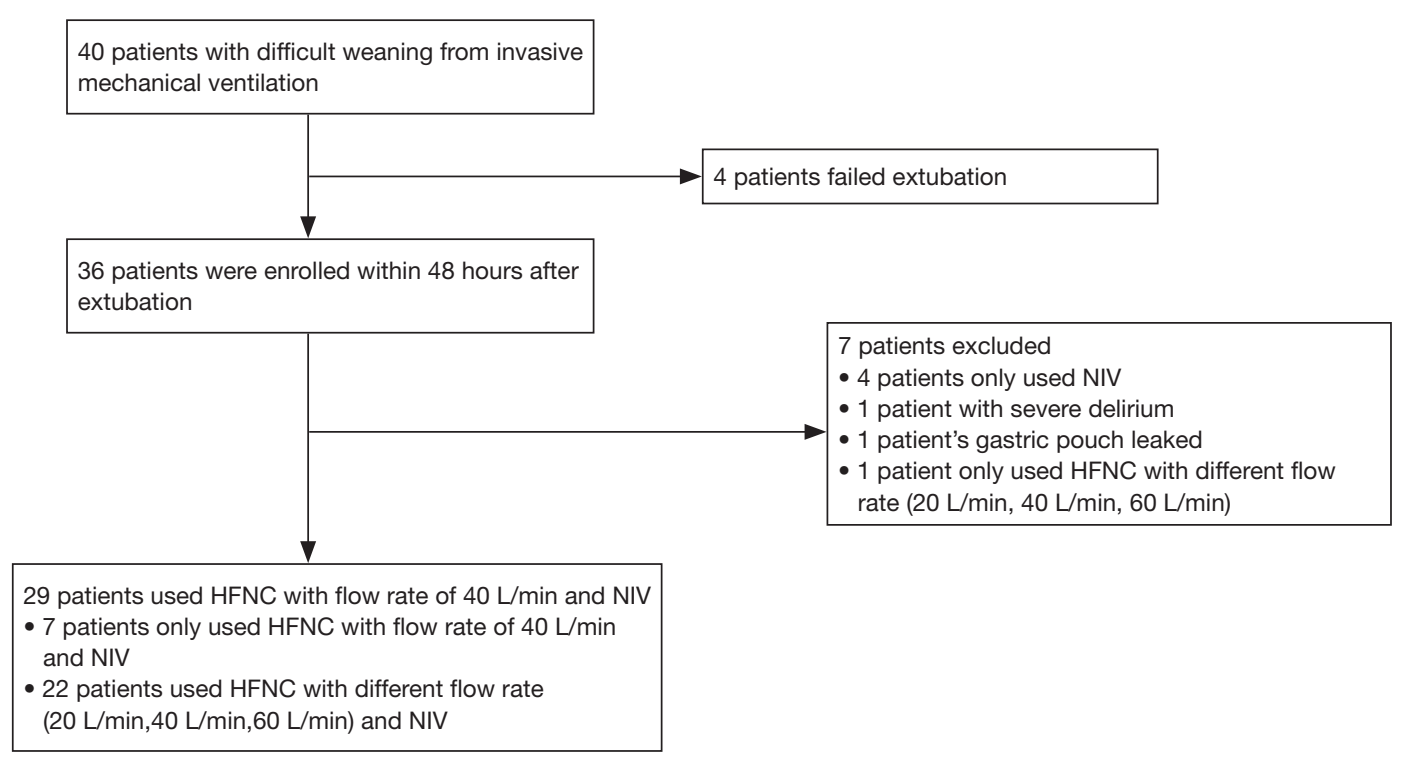

Figure 1 Flowchart. HFNC, high-flow nasal cannula; NIV, non-invasive positive-pressure ventilation.

with at least $60 \mathrm{~min}$ of continuous ventilation for each switch of the sequential mode and 2 min of continuous recording of the relevant data for analysis. The patients oxygen concentration was set at $35-40 \%$ and the HFNC temperature was set at a uniform $37.0{ }^{\circ} \mathrm{C}$. Patients' vital signs were closely monitored during the study period, and as soon as they became unwell, the original respiratory support method and parameters were immediately used and the doctor was promptly informed for further management.

\section{Statistical analysis}

All statistical analyses were performed using $\mathrm{R}$ version 4.0.4. There were missing values in the dataset, and the percentage of missing values was approximately $5 \%$. We performed multiple interpolations based on predictive mean matching on the missing values. Shapiro-Wilk test was used to test whether the distribution of continuous variables was normal, and Levene's test for chi-squared. If continuous variables were normally distributed and satisfied chi-square, they were expressed as mean \pm SD and analyzed using analysis of variance or they were expressed as median and interquartile range and tested non-parametrically using the Kruskal-Wallis test. $\mathrm{P} \leq 0.05$ was considered statistically significant.

\section{Results}

A total of 40 patients who met the criteria for weaning were included in the study. Of these, 4 patients had failed withdraw and 4 were extubated with NIV for respiratory support only; 1 patient was not able to undergo postextraction monitoring because of delirium; 1 patient was not monitored due to gastric bursa leakage, resulting in partial loss of data; 1 patient was randomized to respiratory support with only 20, 40, and $60 \mathrm{~L} / \mathrm{min}$ of HFNC after extubation; 7 patients were randomized to NIV and $40 \mathrm{~L} / \mathrm{min}$ HFNC for respiratory support after extubation, and 22 patients were randomized to NIV and HFNC with different flow rates (20, $40,60 \mathrm{~L} / \mathrm{min}$ ) for respiratory support after extubation, as shown in Figure 1.

Finally, data were collected on 29 patients, including 22 male patients and 7 female patients. Among them, 10 patients with severe pneumonia (34.48\%), 9 patients with AECOPD $31.03 \%$ ), 8 patients were admitted to undergraduate $(27.59 \%)$ after lung transplantation, 1 patient was admitted for lymphangioleiomyomatosis and post-pleural biopsy (3.45\%), 1 case of severe head injury (3.45\%), as shown in Table 1 .

\section{Effect of NIV versus HFNC at $40 \mathrm{~L} / \mathrm{min}$ on respiratory mechanics after extubation in patients on invasive mechanical ventilation}

Twenty-nine patients completed the collection of relevant data. Patients had Pes, Pga, Pdi, PTPes, PTPga, PTPdi, EMGdi, CVEMG, Ti, Te, Ttot, PTPdi/PTPes were not 
Table 1 Patient characteristics at inclusion

\begin{tabular}{lc}
\hline Characteristics & Value \\
\hline Male/female $(\mathrm{n})$ & $22 / 7$ \\
Age (years) & $63.97 \pm 15.34$ \\
Body mass index $\left(\mathrm{kg} / \mathrm{m}^{2}\right)$ & $22.07 \pm 3.61$ \\
PBW (kg) & $58.72 \pm 6.06$ \\
APACHE II score & $18.00 \pm 5.63$ \\
SOFA score & $7.86 \pm 3.41$ \\
Hospital (days) & $35.0(27.0,49.0)$ \\
ICU (days) & $25.0(13.0,33.0)$ \\
Duration of IMV (days) & $18.0(8.0,29.0)$ \\
Duration of NIV (days) & $3.0(2.0,7.0)$ \\
RSBI (times/min·L) & $53.0(33.36,62.50)$ \\
Main reason for intubation, $\mathrm{n}(\%)$ & \\
Severe pneumonia & $10(34.48)$ \\
AECOPD & $9(31.03)$ \\
Lung transplantation & $8(27.59)$ \\
Lymphangiomyomatosis & $1(3.45)$ \\
Severe head injury & $1(3.45)$ \\
\hline Data are shown as mean & \\
\hline &
\end{tabular}

Data are shown as mean \pm standard deviation or median (interquartile range). AECOPD, acute exacerbation of chronic obstructive pulmonary disease; IMV, invasive mechanical ventilation; PBW, predicted body weight; RSBI, Rapid Shallow Breathing Index.

significantly difference in respiratory mechanics between NIV and $40 \mathrm{~L} / \mathrm{min}$ HFNC (all P>0.05), as shown in Table 2.

\section{Discussion}

In recent years, more and more studies have recognized the utility of measuring neural respiratory drive by EMGdi substitution (19-24). High neural respiratory drive may lead to lung or diaphragm injury in patients under mechanical ventilation. And excessive respiratory drive can also cause double-triggering and breath-stacking in assist control modes resulting in higher tidal volumes and injurious lung stress $(25,26)$. This trial found that when HFNC with a flow rate of $40 \mathrm{~L} / \mathrm{min}$ and NIV were used as sequential support after extubation, there was no statistical difference between EMGdi and PTPdi in patients, indicating that there was no significant difference in the neural respiratory drive and the work of breathing.
Although both NIV and HFNC are commonly used for post-extubation sequential therapy, they are not identical in their mechanisms of action, with NIV producing fixed positive airway pressure through a relatively airtight connection and a variable flow rate (27). In contrast, HFNC creates variable positive airway pressure (between 2 and $8 \mathrm{cmH}_{2} \mathrm{O}$ at the pharyngeal level) by producing a warmed and humidified high-flow rate of gas, similar to positive end-expiratory pressure (PEEP) $(28,29)$. Which resembles PEEP and is proportional to the administered gas flow rate, and varies with patient breathing pattern (i.e., breathing with the mouth open or closed).

As shown in Figure 2, the CVes\% was significantly higher and more positive with NIV than HFNC, suggesting that NIV provides greater support than HFNC, but the large dispersion and uneven distribution of Pes with NIV reflects that patients are prone to patient-ventilator dyssynchrony with NIV. During NIV, the patient has clear consciousness and spontaneous breathing. The problem of patient-ventilator dyssynchrony under various reasons is relatively prominent, which affects the patient's subjective feelings and seriously affects the treatment effect. In COPD, when the patient-ventilator dyssynchrony, it causes excessive lung inflation, diaphragm dysfunction, and increased work of breathing, thereby prolonging ICU stay time and even leading to reintubation. However, no significant difference was seen in the PTPdi of patients during the two sequential supports. In a recent study, Grieco et al. found that compared with HFNC, high positive end-expiratory pressure helmet reduces inspiratory effort, reduces Pes and pressure-time product, without affecting carbon dioxide and comfort (30). We speculate that two possibilities exist for the difference in results. First, in that study, the authors used a high positive end expiratory pressure (PEEP) helmet, which was more airtight and able to provide a higher PEEP than in our experiments. Second, because our calculation of PTPdi was made up of both works done by the diaphragm itself and by external respiratory support, with the NIV providing higher support and no significant difference in PTPdi, it is presumed that the work done by the patient's diaphragm is less than that in the HFNC group when the NIV is used. The reasons for airway non-occlusion due to open mouth and nasogastric tubes make HFNC less effective than NIV in providing continuous positive intra-airway pressure during breathing, even though it can reduce upper airway resistance and improve lung compliance (19). Only $40 \mathrm{~L} / \mathrm{min}$ HFNC was used for comparison with the NIV 
Table 2 Effect of HFNC and NIV on respiratory mechanics in patients after extubation

\begin{tabular}{|c|c|c|c|}
\hline Variables & $40 \mathrm{~L} / \mathrm{min} \mathrm{HFNC}$ & NIV & $P$ value \\
\hline $\mathrm{Pga}\left(\mathrm{cmH}_{2} \mathrm{O}\right)$ & $9.05(5.44,10.8)$ & $9.11(7.1,20.12)$ & 0.446 \\
\hline Pdi $\left(\mathrm{cmH}_{2} \mathrm{O}\right)$ & $8.62(4.98,17.9)$ & $8.1(4.54,19.11)$ & 0.9752 \\
\hline PTPes $\left(\mathrm{cmH}_{2} \mathrm{O} \cdot \mathrm{s} / \mathrm{min}\right)$ & $-0.48(-4.48,2.85)$ & $2.24(-0.16,5.28)$ & 0.1127 \\
\hline PTPdi ( $\left.\mathrm{cmH}_{2} \mathrm{O} \cdot \mathrm{s} / \mathrm{min}\right)$ & $10.72(5.76,19.15)$ & $8.77(4.35,17.14)$ & 0.8276 \\
\hline EMGdi $(\mu \mathrm{V})$ & $0.04(0.02,0.06)$ & $0.03(0.02,0.05)$ & 0.8825 \\
\hline CVes\% (\%) & $-7(-23,6)^{\star}$ & $9(-6,20)^{\star}$ & 0.03934 \\
\hline CVEMG\% (\%) & $0.07(0.04,0.13)$ & $0.12(0.06,0.17)$ & 0.1458 \\
\hline Ttot (s) & $3.03 \pm 0.91$ & $3 \pm 0.8$ & 0.899 \\
\hline PTPdi/PTPes & $-1.73(-3.78,1.33)$ & $0.68(-2.16,3.39)$ & 0.08714 \\
\hline Pes/Pdi & $-0.12(-0.43,0.08)^{\star}$ & $0.17(-0.1,0.53)^{\star}$ & 0.02091 \\
\hline
\end{tabular}

*, represents NIV versus HFNC at $40 \mathrm{~L} / \mathrm{min}, \mathrm{P}<0.05$. HFNC, high-flow nasal cannula; NIV, non-invasive positive-pressure ventilation.

in our experiments, and this might not be representative, as $40 \mathrm{~L} / \mathrm{min}$ HFNC theoretically provides less than $60 \mathrm{~L} / \mathrm{min}$ of PEEP. In our previous experiments, we compared the effects of HFNC at different flow rates $(20,40,60 \mathrm{~L} / \mathrm{min})$ on the respiratory mechanics of patients and found no difference in the effects of HFNC at different flow rates on the work of the respiratory muscles and diaphragm electromyography. We therefore conclude that HFNC at different flow rates produces only slight positive airway pressure and does not produce a significant increase in airway pressure with increasing flow rate. As approximately $50 \%$ of patients experience coughing, runny nose, and reduced comfort at a flow rate of $60 \mathrm{~L} / \mathrm{min}$, we believe that $40 \mathrm{~L} / \mathrm{min}$ is the ideal flow rate to provide the same level of respiratory support as other flow rates, while providing optimal patient comfort. The patients in this experiment are breathing spontaneously. We found that Pes/Pdi is higher when using NIV than HFNC and most of them have a positive relationship, also supporting our findings that the patients reduced the work done by the inspiratory-assisted respiratory muscles when using NIV.

Our trial has some limitations. First, the homogeneity of the included patients was not high and we had a small number of cases; more cases will need to be included and analyzed in subgroups in the future. Second, patients' comfort was not adequately assessed and further statistically analyzed using scales, such as the visual numerical scale, but was simply recorded by asking patients about their subjective perceptions of whether they were experiencing discomfort. Third, NIV and HFNC are performed consecutively; the sequence is not fixed, and patients are ventilated for only $1 \mathrm{~h}$ when switching between sequential oxygen therapy modalities. It is possible that prolonging the ventilation time for each sequential oxygen therapy will have a different effect on respiratory mechanics, and the effect of different ventilation times may not be the same. Fourth, NIV and HFNC are consecutive and the sequence is not fixed. When using NIV, the time curve comparison of respiratory waveform, Pes, EMGdi, etc. is not combined to identify the patient-ventilator dyssynchrony.

\section{Outlook}

The effect of different ventilation times on the patient respiratory mechanics (e.g., 2 and 4 h of continuous ventilation) should be compared in future studies in order to provide better sequential support times for clinical purposes. The incidence and type of patient-ventilator dyssynchrony should also be compared by combining airway pressure-time, esophageal pressure-time waveforms, 

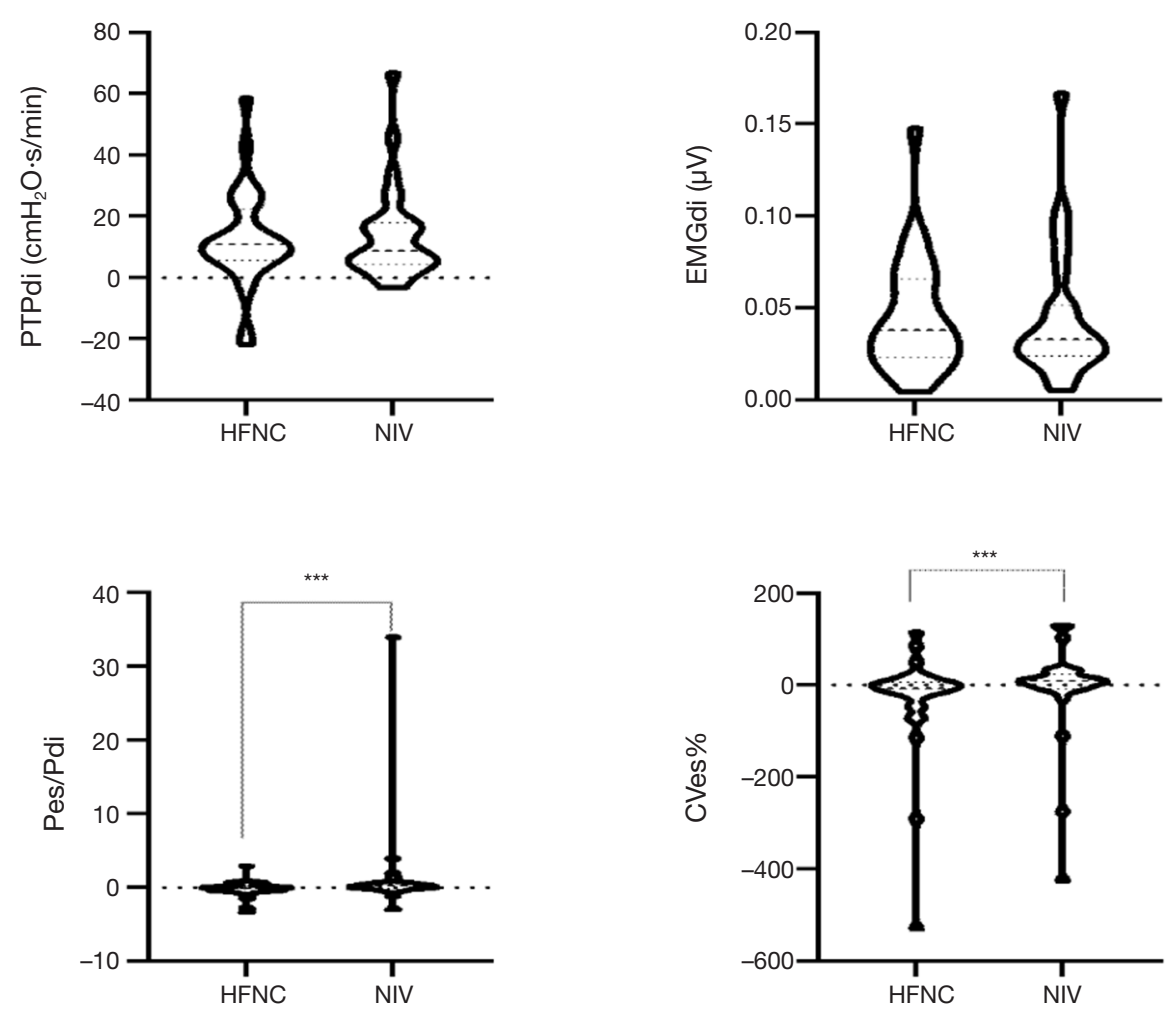

Figure 2 Violin diagrams for CVes\%, EMGdi, Pes/Pdi, and PTPdi. PTPdi and EMGdi were not statistically different, and Ped/Pdi and $\mathrm{CVes} \%$ were statistically significantly different (***, $\mathrm{P}<0.05)$. HFNC, high-flow nasal cannula; NIV, non-invasive positive-pressure ventilation.

and EMGdi.

\section{Conclusions}

The sequential NIV and HFNC can be tolerated in patients with such difficult weaning off mechanical ventilation after extubation, and more patients tend to choose HFNC subjectively. Compared with HFNC, NIV reduces the work of adjunctive respiratory muscle, but the patient's Pes dispersion is high when NIV is used, and it is necessary to pay attention to patient-ventilator coordination in clinical practice. We recommend alternating HFNC and NIV during the sequential respiratory therapy after extubation.

\section{Acknowledgments}

Funding: Guangzhou Institute of Respiratory Health/2019 Clinical Independent Exploration Project of National Clinical Research Center of the First Hospital of Guangzhou Medical University (Grant No.
2019GIRHZ10); Emergency Key Program of Guangzhou Laboratory (Grant No. EKPG21-17).

\section{Footnote}

Reporting Checklist: The authors have completed the STROBE reporting checklist. Available at https://dx.doi. org/10.21037/atm-21-3408

Data Sharing Statement: Available at https://dx.doi. org/10.21037/atm-21-3408

Conflicts of Interest: All authors have completed the ICMJE uniform disclosure form (available at https://dx.doi. org/10.21037/atm-21-3408). The authors have no conflicts of interest to declare.

Ethical Statement: The authors are accountable for all aspects of the work in ensuring that questions related to the accuracy or integrity of any part of the work 
are appropriately investigated and resolved. The study complied with medical ethics standards and was approved by the Ethics Committee of the First Affiliated Hospital of Guangzhou Medical University (approval No.: 2020159). Informed consent was obtained from the patient or next of kin for treatment and monitoring. All procedures performed in this study involving human participants were in accordance with the Declaration of Helsinki (as revised in 2013).

Open Access Statement: This is an Open Access article distributed in accordance with the Creative Commons Attribution-NonCommercial-NoDerivs 4.0 International License (CC BY-NC-ND 4.0), which permits the noncommercial replication and distribution of the article with the strict proviso that no changes or edits are made and the original work is properly cited (including links to both the formal publication through the relevant DOI and the license). See: https://creativecommons.org/licenses/by-nc-nd/4.0/.

\section{References}

1. Funk GC, Anders S, Breyer MK, et al. Incidence and outcome of weaning from mechanical ventilation according to new categories. Eur Respir J 2010;35:88-94.

2. Navalesi P, Bruni A, Garofalo E, et al. Weaning off mechanical ventilation: much less an art, but not yet a science. Ann Transl Med 2019;7:S353.

3. Zhou X, Yao S, Dong P, et al. Preventive use of respiratory support after scheduled extubation in critically ill medical patients-a network meta-analysis of randomized controlled trials. Crit Care 2020;24:370.

4. Ou X, Hua Y, Liu J, et al. Effect of high-flow nasal cannula oxygen therapy in adults with acute hypoxemic respiratory failure: a meta-analysis of randomized controlled trials. CMAJ 2017;189:E260-7.

5. Rochwerg B, Brochard L, Elliott MW, et al. Official ERS/ ATS clinical practice guidelines: noninvasive ventilation for acute respiratory failure. Eur Respir J 2017;50:1602426.

6. Spicuzza L, Schisano M. High-flow nasal cannula oxygen therapy as an emerging option for respiratory failure: the present and the future. Ther Adv Chronic Dis 2020;11:2040622320920106.

7. Akashiba T, Ishikawa Y, Ishihara H, et al. The Japanese Respiratory Society Noninvasive Positive Pressure Ventilation (NPPV) Guidelines (second revised edition). Respir Investig 2017;5 5:83-92.

8. Branson RD. Patient-ventilator interaction: the last 40 years. Respir Care 2011;56:15-24.

9. Liu J, Duan J, Bai L, et al. Noninvasive Ventilation Intolerance: Characteristics, Predictors, and Outcomes. Respir Care 2016;61:277-84.

10. Delclaux C, L'Her E, Alberti C, et al. Treatment of acute hypoxemic nonhypercapnic respiratory insufficiency with continuous positive airway pressure delivered by a face mask: A randomized controlled trial. JAMA 2000;284:2352-60.

11. Maggiore SM, Idone FA, Vaschetto R, et al. Nasal highflow versus Venturi mask oxygen therapy after extubation. Effects on oxygenation, comfort, and clinical outcome. Am J Respir Crit Care Med 2014;190:282-8.

12. Hernández G, Vaquero C, Colinas L, et al. Effect of Postextubation High-Flow Nasal Cannula vs Noninvasive Ventilation on Reintubation and Postextubation Respiratory Failure in High-Risk Patients: A Randomized Clinical Trial. JAMA 2016;316:1565-74.

13. Hernández G, Vaquero C, González P, et al. Effect of Postextubation High-Flow Nasal Cannula vs Conventional Oxygen Therapy on Reintubation in Low-Risk Patients: A Randomized Clinical Trial. JAMA 2016;315:1354-61.

14. Granton D, Chaudhuri D, Wang D, et al. High-Flow Nasal Cannula Compared With Conventional Oxygen Therapy or Noninvasive Ventilation Immediately Postextubation: A Systematic Review and Meta-Analysis. Crit Care Med 2020;48:e1129-36.

15. Ni YN, Luo J, Yu H, et al. Can high-flow nasal cannula reduce the rate of reintubation in adult patients after extubation? A meta-analysis. BMC Pulm Med 2017;17:142.

16. Tan D, Walline JH, Ling B, et al. High-flow nasal cannula oxygen therapy versus non-invasive ventilation for chronic obstructive pulmonary disease patients after extubation: a multicenter, randomized controlled trial. Crit Care 2020;24:489.

17. Thille AW, Muller G, Gacouin A, et al. Effect of Postextubation High-Flow Nasal Oxygen With Noninvasive Ventilation vs High-Flow Nasal Oxygen Alone on Reintubation Among Patients at High Risk of Extubation Failure: A Randomized Clinical Trial. JAMA 2019;322:1465-75.

18. Boles JM, Bion J, Connors A, et al. Weaning from mechanical ventilation. Eur Respir J 2007;29:1033-56.

19. Suh ES, Pompilio P, Mandal S, et al. Autotitrating external positive end-expiratory airway pressure to abolish expiratory flow limitation during tidal breathing in patients with severe COPD: a physiological study. Eur Respir J 2020;56:1902234. 
20. Schaeffer MR, Ryerson CJ, Ramsook AH, et al. Neurophysiological mechanisms of exertional dyspnoea in fibrotic interstitial lung disease. Eur Respir J 2018;51:1701726.

21. Elbehairy AF, Guenette JA, Faisal A, et al. Mechanisms of exertional dyspnoea in symptomatic smokers without COPD. Eur Respir J 2016;48:694-705.

22. Domnik NJ, Walsted ES, Langer D. Clinical Utility of Measuring Inspiratory Neural Drive During Cardiopulmonary Exercise Testing (CPET). Front Med (Lausanne) 2020;7:483.

23. Faisal A, Alghamdi BJ, Ciavaglia CE, et al. Common Mechanisms of Dyspnea in Chronic Interstitial and Obstructive Lung Disorders. Am J Respir Crit Care Med 2016;193:299-309.

24. Boyle KG, Mitchell RA, Ramsook AH, et al. The effect of diaphragm fatigue on the multidimensional components of dyspnoea and diaphragm electromyography during exercise in healthy males. J Physiol 2020;598:3223-37.

25. Liu L, Liu H, Yang Y, et al. Neuroventilatory efficiency and extubation readiness in critically ill patients. Crit Care
2012;16:R143.

26. Telias I, Brochard L, Goligher EC. Is my patient's respiratory drive (too) high? Intensive Care Med 2018;44:1936-9.

27. Papazian L, Corley A, Hess D, et al. Use of high-flow nasal cannula oxygenation in ICU adults: a narrative review. Intensive Care Med 2016;42:1336-49.

28. Di Mussi R, Spadaro S, Stripoli T, et al. High-flow nasal cannula oxygen therapy decreases postextubation neuroventilatory drive and work of breathing in patients with chronic obstructive pulmonary disease. Crit Care 2018;22:180.

29. Spoletini G, Alotaibi M, Blasi F, et al. Heated Humidified High-Flow Nasal Oxygen in Adults: Mechanisms of Action and Clinical Implications. Chest 2015;148:253-61.

30. Grieco DL, Menga LS, Raggi V, et al. Physiological Comparison of High-Flow Nasal Cannula and Helmet Noninvasive Ventilation in Acute Hypoxemic Respiratory Failure. Am J Respir Crit Care Med 2020;201:303-12.

(English Language Editor: R. Scott)
Cite this article as: Wang SY, Liang HW, Lu GS, Jiang ZJ, Zhang BZ, Deng QX, Sun QW, Lin ZM, Chen Q, Yang C, $\mathrm{Xu}$ YD, Sang L. Effect of sequential high-flow nasal cannula oxygen therapy and non-invasive positive-pressure ventilation in patients with difficult weaning from mechanical ventilation after extubation on respiratory mechanics. Ann Transl Med 2021;9(15):1251. doi: 10.21037/atm-21-3408 